\title{
Morphological Classification of Arch of Frohse and Its Implication in Compression of Deep Branch of Radial Nerve
}

\author{
Syed Rehan Hafiz Daimi ${ }^{1}$, Srinivasa Rao Bolla ${ }^{2}$, Moizuddin Jawaduddin Khwaja ${ }^{3}$, Sanket Dadarao Hiware ${ }^{4}$, \\ Shajiya Sarwar Moosa ${ }^{5}$, Yousuf Begum ${ }^{6}$, Siraj Ahmed Hasham Shaikh7, Asim Mohsin Badaam ${ }^{8}$
}

1, 3, 4, 5, 6, 7, 8 Department of Anatomy, College of Medicine, Imam Abdulrahman Bin Faisal University, Dammam, Kingdom of Saudi Arabia, ${ }^{2}$ Department of Biomedical Sciences, School of Medicine, Nazarbayev University, Nur-Sultan, Kazakhstan.

\section{ABSTRACT}

\section{BACKGROUND}

Arcade of Frohse (AF) is a tendinous superior margin of superficial layer of supinator muscle which was first described by Frohse and Frankel in 1908. Since then it has been studied by many authors and held accountable as one of the essential components for compression of deep branch of radial nerve (DBRN) which leads to radial tunnel syndrome. Considering $\mathrm{AF}$ as an important element of compression, we made an attempt to classify it on the basis of its shape and to find out if any particular shape has a predominant role in compression of the nerve. We also observed the structure of superior and inferior margin of the supinator muscle.

\section{METHODS}

This study was conducted among 80 (70 males and 10 females) formalin fixed upper limbs present in the Department of Anatomy. The limbs were maintained in supine with slightly flexed position and dissection was performed to expose the supinator muscle. The proximal and distal borders of supinator muscles were examined meticulously with the help of magnified lens. The morphometric measurements were taken with the help of a digital caliper.

\section{RESULTS}

The FA is classified into four categories as loop, high arc, low arch and linear shaped. The most frequent shape observed was arch shaped (high and low arch) about $66 \%$, followed by loop shaped (30\%) and least was linear shaped (2.5\%). On the basis of structure, the proximal and distal margin of supinator muscle was reported to be tendinous in majority of the cases. The distance of the AF from the fixed reproducible anatomical landmark like inter epicondylar line (IEL) was measured and the average distance found was $3.36 \mathrm{~cm}$.

\section{CONCLUSIONS}

Knowledge of different shapes would aid surgeons and radiologists for better approach towards diagnosis and management of supinator syndrome. The morphometric finding can be useful for surgeons to locate the superior margin of supinator (AF) in surgical procedures for decompression of DBRN in supinator syndrome.

\section{KEY WORDS}

Arcade of Frohse, Inter Epicondylar Line, Supinator Muscle, Deep Branch of Radial Nerve and Radial Tunnel Syndrome
Corresponding Author: Dr. Syed Rehan Hafiz Daimi, Department of Anatomy, College of Medicine, Imam Abdulrahman Bin Faisal University, Dammam, Kingdom of Saudi Arabia. E-mail: srdaimi@iau.edu.sa

DOI: $10.14260 /$ jemds $/ 2021 / 494$

How to Cite This Article:

Daimi SRH, Bolla SR, Khwaja MJ, et al. Morphological classification of arch of frohse and its implication in compression of deep branch of radial nerve. J Evolution Med Dent Sci 2021;10(31):2412-2415, DOI: 10.14260/jemds/2021/494

Submission 23-03-2021, Peer Review 28-05-2021, Acceptance 05-06-2021, Published 02-08-2021.

Copyright (c) 2021 Syed Rehan Hafiz Daimi et al. This is an open access article distributed under Creative Commons Attribution License [Attribution 4.0 International (CC BY 4.0)] 


\section{BACKGROUND}

The radial tunnel is the commonest site of radial nerve entrapment neuropathy. It is also referred to as radial tunnel syndrome (RTS), posterior interosseous nerve syndrome (PIN) or supinator syndrome. ${ }^{1,2,3,4}$ Radial tunnel is a musculoaponeurotic furrow or space extending from lateral epicondyle of the humerus to distal edge of the supinator muscle. ${ }^{3}$ Various studies have been conducted to explore causes of entrapment neuropathy of the deep branch of radial nerve (DBRN) in the radial tunnel. It was found that various anatomical elements as well as pathological conditions were responsible for entrapment. The anatomical elements responsible for compression reported were; medial border of extensor carpi radialis brevis muscle, fibrous bands of radiohumeral joint, radial recurrent vessels, proximal and distal margins of supinator muscle.5,6,7 Besides these, some other causes mentioned were intermuscular fibrous septum connecting brachialis and brachioradialis muscle and repetitive pronation and supination movements. ${ }^{2,4}$ The pathological conditions responsible for compression were; fracture and dislocation of radial head, lipoma, tumor ganglion, bursitis, rheumatoid arthritis etc. ${ }^{3}$ Among all, the most frequently reported factor responsible for compression of DBRN was the tendinous superior border of supinator muscle which is also referred as Arch of frohse (AF). 1,2,3,4,8,9,10,11

There is no typical sign to diagnose RTS, however the most obvious symptom is the pain in the extensor muscles of the forearm, which is aggravated by supination and pronation movements. ${ }^{11}$ Individuals working as music directors, athletes, violin players which require chronic repetition of pronation and supination are at high risk to develop RTS.3,12 The management of RTS includes both surgical and nonsurgical treatments. The goal of the treatment is to relieve the pain and encourage the patient to return to work or previous activities.3,13 Although the success rate of non-surgical treatment is uncertain, the common methods practiced are use of anti- inflammatory, immobilization of limb, physiotherapy, blocking radial nerve by local anesthetic and ultrasound massage. The surgical management is to release the nerve from the arcade of Frohse and ligating the radial recurrent blood vessels. ${ }^{3}$ Apparently surgical management of RTS provides excellent results and success rate is $67 \%$ to $95 \%$. $^{14,15,16,17}$

Many anatomical and clinical studies have been carried out on the AF to investigate its structural composition and morphometery. Literature is scanty regarding its morphology, especially about the shape of the arch. To understand the complete pathology and for surgical treatment of the radial tunnel syndrome it is essential to explore the complex anatomical relationship of supinator muscle and DBRN.

The main purpose of the present study was to classify different shapes of the AF and to determine their prevalence. This study also intended to provide relevant morphometric data for localizing AF by establishing its relation to fixed reproducible anatomical landmark. This study would be helpful to determine the nature of superior border of supinator muscle and for the surgeon to localize the AF during the DBRN decompression surgeries.

\section{METHODS}

This is a cadaver based morpologic study, conducted on 80 (70 males and 10 females) formalin fixed upper limbs present in the Department of Anatomy, College of Medicine, Dammam, Saudi Arabia, from March 2019 to April 2020. All limbs were free from any detectable pathology and scar.

The limbs were maintained in supine with slightly flexed position and dissection was performed to expose the supinator muscle. The proximal and distal borders of the supinator muscle were examined meticulously with the help of magnified lens. The shape of $\mathrm{AF}$ was recorded and photographed. An attempt was made to classify the AF in different shapes namely; loop, low arch, high arch and linear shaped.

The superior and inferior borders of the supinator muscle was classified according to Debouck and Rooze into four different types - tendinous, musculo-tendinous, muscular, and membranous; resembled the margin pearly - white fibers, alternate tendinous and muscular fibers, resembled muscle or whitish, supple and unorganized tissue respectively. ${ }^{4}$

Following measurements were taken with the help of digital calipers in supine position.

1. The distance from the midpoint of the IEL to the proximal (superior) border of supinator muscle.

2. Distance between proximal and distal borders of supinator muscle.

\section{Statistical Analysis}

Data was collected and processed under SPSS package.

\section{RESULTS}

The AF was classified according to shape into four categories namely: loop shaped, high arch shaped, low arch shaped and linear shaped (Figure 1). Loop shaped AF was observed in 24 out of 80 cases (30\%). The high arch and low arch shaped AF was found in 27 cases each (33.7 \%) and linear shaped was seen in 2 cases (2.5\%). Prevalence of different shapes of AF is shown in Table 1. Other classification of AF was based on structure; according to it AF was classified into four types; tendinous, musculotendinous, muscular and membranous. The superior border of the superficial layer of supinator was tendinous in 38 out of 80 cases ( $45 \%), 18$ (22.5\%) on the right side and 20 (25\%) on the left side (Fig. 1a).

Musculotendinous AF was observed in $32(38.7 \%)$ cases (Fig - 1c), $21(26.2 \%)$ on the right side and $11(13.7 \%)$ on the left side. Muscular AF was observed in 10 (12.5\%) cases (Fig 1d) - 4 (5\%) on right side and $6(7.5 \%)$ on left side. Membranous AF was observed in single (1.2\%) case (Fig. 2c) on left side. The prevalence of different structures of superior border of supinator (AF) has been shown in Table 2. The inferior border of supinator muscle was tendinous in 40 (50 $\%)$ cases. Musculotendinous and muscular inferior border of supinator was observed in 26 (32.5\%) and 14 (17.5\%) cases respectively. We didn't find membranous inferior border in any case. 


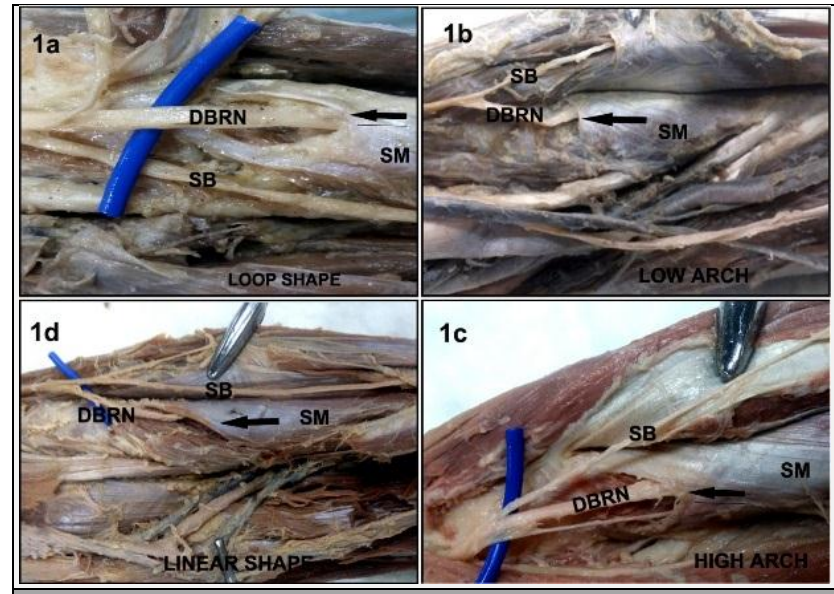

Figure 1. Photograph Showing Dissected Anterior View of Elbows. It Shows Four Shapes of Arch of Frohse (AF). The Arrow in Fig. 1a Indicate Loop Shape AF; Fig. 1 b Reveals Low Arch AF; Fig. 1c Indicates High Arch and Fig. 1d Reveals Linear Shape of AF. DBRN - Deep Branch of Radial Nerve, SB - Superficial Branch of Radial Nerve, SM - Supinator Muscle

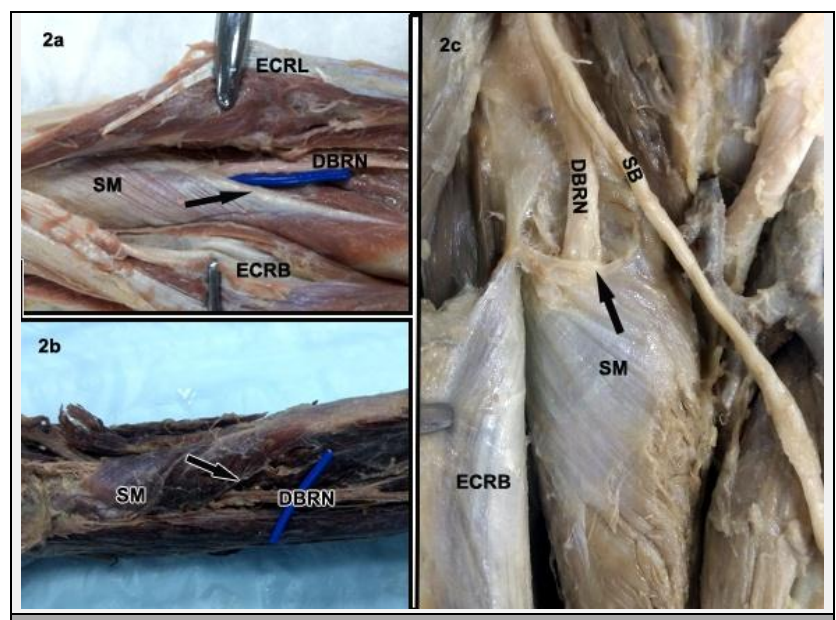

Figure 2. Photograph Showing Dissected Anterior View of Forearms. Th Arrow in Fig. 2a Indicates Tendinous Structure of Inferior Margin of Supinator MUSCLE and Fig. $2 b$ Indicates Musculus Inferior Margin. Fig. $2 c$ Indicates the Membranous Superior Border of Supinator Muscle

\begin{tabular}{|cccc|}
\hline Sl. No & Shapes & Number (48) & Percentage \\
1. & Loop & 24 & $30 \%$ \\
2. & High arch & 27 & $33.7 \%$ \\
3. & Low arch & 27 & $33.7 \%$ \\
4. & Linear & 2 & $2.5 \%$ \\
\hline \multicolumn{4}{|c}{ Table1: Prevalence of Different Shapes of $\boldsymbol{A F}$} \\
\hline
\end{tabular}

\begin{tabular}{|cccccc|}
\hline $\begin{array}{c}\text { Supinator } \\
\text { Muscle }\end{array}$ & Side & Tendinous & $\begin{array}{c}\text { Musculo- } \\
\text { tendinous }\end{array}$ & Muscular & $\begin{array}{c}\text { Membra- } \\
\text { nous }\end{array}$ \\
Superior Border & Right & $18(22.5 \%)$ & $21(26.2 \%)$ & $4(5 \%)$ & - \\
(AF) & Left & $20(25 \%)$ & $11(13.7 \%)$ & $6(7.5 \%)$ & $1(1.2 \%)$ \\
& Total & $38(45 \%)$ & $32(38.7 \%)$ & $10(12.5 \%)$ & $1(1.2 \%)$ \\
Inferior Border & Right & $26(32.5 \%)$ & $13(16.2 \%)$ & $4(5 \%)$ & - \\
& Left & $14(17.5 \%)$ & $13(16.2 \%)$ & $10(12.5 \%)$ & - \\
& Total & $40(50 \%)$ & $26(32.5 \%)$ & $14(17.5 \%)$ \\
\hline \multicolumn{6}{c}{ Table 2. The Prevalence of Different Structures of } \\
Superior (AF) and Inferior Borders of the Supinator \\
\hline
\end{tabular}

The average distance between midpoint of the interepicondylar line (IEL) and midpoint of the superior border of supinator (AF) was $3.36 \mathrm{~cm}$ (range $2-5.2 \mathrm{~cm}$ ). While the average distance between superior and inferior margin of supinator muscle recorded was $4.08 \mathrm{~cm}$ (range $2.6-7.5 \mathrm{~cm}$ ). We didn't find any significant difference in male and female findings.

\section{DISCUSSION}

The present study was conducted in an attempt to make a classification of the shapes of AF. Also to provide useful morphometric data to locate the proximal border of supinator muscle from reproducible anatomical landmark, as this would be useful for surgeons during decompression surgeries. Although many authors have worked on AF and provided useful information about its structure, none of them had described its shape which would be an important criteria in entrapment neuropathy of the DBRN. To the best of our knowledge and in the light of available literature, this is the first study to classify the shapes of proximal margin of supinator (AF) muscle. We have classified the AF into four types: loop, high arch, low arch and linear shaped. Most of the authors had mentioned it as semicircular shape.18,19 We observed that the high arch and low arch shapes of AF were more frequent, contributing about $33.7 \%$ each, followed by loop shape (30\%) and the least was linear shape (2.5\%). It could be assumed that loop shaped AF with tendinous margin seem to be more prone for compression as it surrounds the nerve completely and provides little room for movement. Ozkan. M et al. quoted that according to Spinner, entrapment may occur at the AF when it is thick tendinous with narrow opening for passage of the nerve. ${ }^{9}$

Our findings on the nature of the superior border of the superficial layer of the supinator muscle found disparity with findings of Konjengbam and Elangbam. They found tendinous border in $87 \%$ and musculotendinous in $13 \% .{ }^{8}$ On contrary we observed tendinous in $45 \%$ and musculotendinous in $39 \%$. They did not find the membranous and muscular type and we observed it in $12 \%$ and $1.2 \%$ respectively. Our results are in accordance to that of C Debouck and M Rooze. ${ }^{4}$ We have not compared the result of those studies in which classification was according to the Prasartritha et al. because of different classification criteria. ${ }^{11}$ The comparison of prevalence of different types of structures of AF in different studies has been mentioned in Table 3.

\begin{tabular}{|ccccc|}
\hline Authors & Tendinous & Musculotendinous & Muscular & Membranous \\
Present Study & $45 \%$ & $48 \%$ & $12 \%$ & $1 \%$ \\
$\begin{array}{c}\text { Konjengbam } \\
\text { and Elangbam. }\end{array}$ & $87 \%$ & $13 \%$ & 0 & 0 \\
$\begin{array}{c}\text { Debouck and } \\
\text { Rooze 4 }\end{array}$ & 64 & 22 & 12 & 2 \\
$\begin{array}{c}\text { Charles Berton } \\
\text { et al. }{ }^{1}\end{array}$ & 66 & 17 & 17 & 0 \\
$\begin{array}{c}\text { Vaishali and } \\
\text { Lakshmi }{ }^{20}\end{array}$ & $10 \%$ & 22 & 0 & 32 \\
\hline \multicolumn{4}{c}{ Table 3. Comparison of Prevalence of Different } \\
Types of Structures of AF in Different Studies \\
\hline \multicolumn{4}{c}{} \\
\hline
\end{tabular}

Although our observation is similar to other workers with some exceptions, most of them had noted high prevalence of the tendinous arch of $\mathrm{AF}$ while we found increased frequency in the muscluotendinous type. Vaishali and Lakshmi noted membranous AF in $32 \%$ which was quiet high as compared to $2 \%$ in our study. ${ }^{20}$ Our observations regarding the inferior border of the supinator muscle are similar with the findings of Konjengbam and Elangbam with only difference that we did not find membranous inferior border in any of our cases against $2 \%$ reported by them. ${ }^{8}$ There is great disparity in observation reported by Vaishali and Lakshmi, as they have reported more cases of muscular and membranous inferior 
margins and less tendinous margin as compared to the present study. ${ }^{20}$ Inferior margin of supinator muscle is also considered as an element for compression of DBRN and would be one of the reasons to cause radial tunnel syndrome. ${ }^{11}$

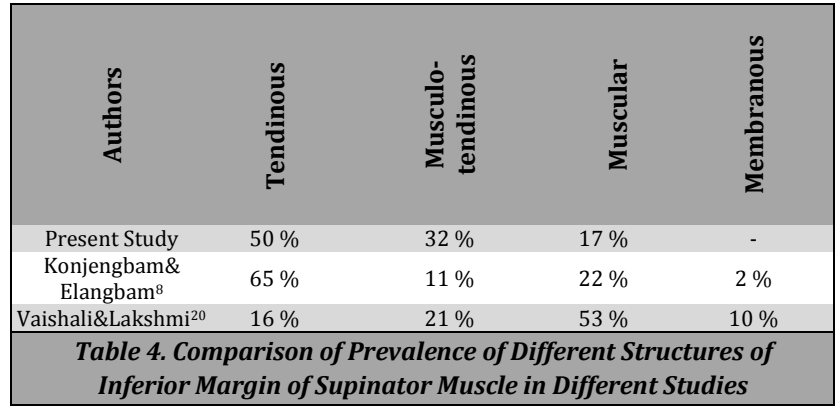

In the present study, the distance between the $\mathrm{AF}$ from inter epicondylar line (IEL) was $3.36 \mathrm{~cm}$ (range $2 \mathrm{~cm}-5.2 \mathrm{~cm}$ ). While Berton C et al. has noted this distance as $41.1 \mathrm{~mm}$ which was slightly on the greater side. ${ }^{1}$ Our findings are almost similar with Konjengbam and Elangbam. ${ }^{8}$ Inter epicondylar line was selected for measurement because it is a fixed and an easy anatomical landmark. This parameter (the distance between the AF from IEL) would be greatly beneficial for the surgeons to locate exact position of $\mathrm{AF}$ while performing decompression surgeries and to avoid complications.

We recorded an average distance between proximal and distal border of supinator as $4.08 \mathrm{~cm}$ (range $2.6-7.5 \mathrm{~cm}$ ) which is almost in line with the findings of Berton $\mathrm{C}$ et al. and Riffaud L et al.1,12

\section{CONCLUSIONS}

This study has attempted to classify the AF on the basis of its shapes and revealed four different types of AF as loop, low arch, high arch and linear shaped. The arch shape exceeds in number as compared to the other shapes. Knowledge of different shapes of $\mathrm{AF}$ would aid surgeons and radiologists for better approach towards diagnosis and management of supinator syndrome. On the basis of structure, $\mathrm{AF}$ and inferior margin of the superficial layer of supinator was found to be more of tendinous nature. We have also deduced an effective morphometric data to locate AF from IEL and it could be very useful for surgeons during DBRN decompression surgery.

Data sharing statement provided by the authors is available with the full text of this article at jemds.com.

Financial or other competing interests: None.

Disclosure forms provided by the authors are available with the full text of this article at jemds.com.

\section{REFERENCES}

[1] Berton C, Wavreille G, Lecomte F, et al. The supinator muscle anatomical bases for deep branch of the radial nerve entrapment. Surg Radiol Anat 2013;35(3):217-24.

[2] Cravens G, Kline DG. Posterior interosseous nerve palsies. Neurosurgery 1990;27(3):397-402.

[3] Clavert P, Lutz JC, Adam P, et al. Frohse's arcade is not the exclusive compression site of the radial nerve in its tunnel. Orthop Traumatol Surg Res 2009;95(2):114-8.

[4] Debouck C, Rooze M. The arcade of frohse: an anatomic study. Surg Radiol Anat 1995;17(3):245-8.

[5] Eversmann WW. Operative hand surgery. $2^{\text {nd }}$ edn. Vol. 2. Edinburgh: Churchill Livingstone 1988:1454-60.

[6] Eaton CJ, Lister GD. Radial nerve compression. Hand Clin 1992;8(2):345-57.

[7] Fuss FK, Wurzl GH. Radial nerve entrapment at the elbow: surgical anatomy. J Hand Surg Am 1991;16(4):742-7.

[8] Konjengbam M, Elangbam J. Radial nerve in the radial tunnel: anatomic sites of entrapment neuropathy. Clin Anat 2004;17(1):21-5.

[9] Ozkan M, Bacakoglu AK, Gul O, et al. Anatomic study of posterior interosseous nerve in the arcade of Frohse. J Shoulder Elbow Surg 1999;8(6):617-20.

[10] Ozturk A, Kutlu C, Taskara N, et al. Anatomic and morphometric study of the arcade of Frohse in cadavers. Surg Radiol Anat 2005;27(3):171-5.

[11] Prasartritha T, Liupolvanish P, Rojanakit A. A study of the posterior interosseous nerve (PIN) and the radial tunnel in 30 Thai cadavers. J Hand Surg Am 1993;18(1):107-12.

[12] Riffaud L, Morandi X, Godey B, et al. Anatomic bases for the compression and neurolysis of the deep branch of the radial nerve in the radial tunnel. Surg Radiol Anat 1999;21(4):229-33.

[13] Cleary CK. Management of radial tunnel syndrome: a therapist's clinical perspective. J Hand Ther 2006;19(2):186-91.

[14] Lister GD, Belsole RB, Kleinert HE. The radial tunnel syndrome. J Hand Surg Am 1979;4(1):52-9.

[15] Roles NC, Maudsley RH. Radial tunnel syndrome: resistant tennis elbow as a nerve entrapment. J Bone Joint Surg Br 1972;54(3):499-508.

[16] Jebson PJ, Engber WD. Radial tunnel syndrome: longterm results of surgical decompression. J Hand Surg Am 1997;22(5):889-96.

[17] Moss SH, Switzer HE. Radial tunnel syndrome: a spectrum of clinical presentations. J Hand Surg Am 1983;8(4):41420.

[18] Sunderland S. Nerve and nerve injuries. $2^{\text {nd }}$ edn. Edinburgh: Churchill Livingstone 1978:802-26.

[19] Spinner M. The arcade of frohse and its relationship to posterior interosseous nerve paralysis. J Bone Joint Surg Br 1968;50(4):809-12.

[20] Ahire VP, Rajgopal L. A study of radial nerve and its deep branch in the cubital fossa. International Journal of Recent Trends in Science and Technology 2014;12(2):247-9. 